\title{
EL LAZARILLO Y ALFONSO DE VALDÉS
}

La reciente edición del Lazarillo por las profesoras Rosa Navarro y Milagros Rodríguez tiene la muy llamativa novedad de estar denodadamente impresa como obra de Alfonso de Valdés ${ }^{1}$, tal como a fines del siglo xIx y comienzos del xx hubo quienes denodadamente pusieron como autor a Diego Hurtado de Mendoza. Pero tiene también otras novedades que vale la pena comentar.

Dejando a un lado, de momento, a Alfonso de Valdés, comenzaré con la estructura que R.N. da al libro. El Lazarillo se ha dividido siempre en ocho secciones: un prólogo y siete tractados; pero R.N. lo divide en diez, a saber: Prólogo, Argumento, Dedicatoria y los siete tractados. Dice que el Lazarillo que conocemos es un "texto incompleto": alguien "arrancó" (¿del manuscrito original?) el folio que contenía el Argumento, "parte esencial para la comprensión de la obra" (p. 15); este Argumento, con su "presentación de los personajes", debería estar entre el Prólogo y la Dedicatoria, y "ofrecería datos sobre la relación entre el emisor y el destinatario” (p. 109). La Dedicatoria, en cambio, sí existe, y se imprime aquí en página aparte. Nadie la había descubierto - dice R.N.- a causa de que, al arrancarse el folio del Argumento, quedó yuxtapuesta al Prólogo, como si constituyera su párrafo final. He aquí su razonamiento: el Prólogo "va di-

1 Alfonso de Valdés, La vida de Lazarillo de Tormes, y de sus fortunas y adversidades, introd. de Rosa Navarro Durán; ed. y notas de Milagros Rodríguez Cáceres, Octaedro, Madrid, 2003; 219 pp. (Biblioteca Octaedro, núm. 15). Es Rosa Navarro (abreviaré en adelante "R.N.") quien sostiene la tesis de la paternidad de Valdés. En la bibliografía se mencionan dos libros suyos que confieso no haber leído: "Lazarillo de Tormes" de Alfonso de Valdés, Semyr, Salamanca, 2002, y Alfonso de Valdés, autor del "Lazarillo de Tormes", Gredos, Madrid, 2003. No pienso leerlos: a juzgar por los resúmenes que de ellos se ofrecen en las pp. 97-98, no dicen más de lo que hay en la Introducción (pp. 7-90) del libro que estoy comentando, y no es de creer que se haya quedado en el tintero algún argumento de importancia. -En estas páginas me refiero sólo a R.N., aun en citas tomadas de las notas de Milagros Rodríguez, pues ésta, invariablemente, se hace eco de las opiniones de R.N. 
rigido a los lectores en general", y de pronto hay un "brusco cambio de destinatario", un "salto inexplicable", un "vacío” entre Prólogo y Dedicatoria.

El razonamiento es muy endeble, pues el Prólogo y la Dedicatoria pudieron quedar juntos sin necesidad de "arrancar" un folio; y la hipótesis de que falta un Argumento es de todo punto gratuita ${ }^{2}$. En cuanto a lo otro, yo no veo que haya "cambio", "salto" ni "vacío" alguno. Lázaro menciona ciertamente a posibles lectores de su autobiografía, pero no se dirige a ellos; a quien se dirige, desde el principio hasta el final, es a cierta persona sabedora de que él, Lázaro, se declara plenamente satisfecho de su vida (a pesar de que vive de manera muy modesta), y, con explicable curiosidad por un caso tan insólito ( rara avis), le ha pedido que cuente cómo puede ser eso. Lázaro accede a la petición y comienza así su respuesta: La idea de contar mi vida me parece bien, y me gustaría que tuviera muchos lectores. Algunos se divertirán con mis aventuras, pero otros, los capaces de ahondar, sabrán descubrir que no todo es "donaires", y verán con qué justicia me ufano de vivir pese a tantas fortunas, peligros y adversidades $^{3}$; y, ya que Vuestra Merced quiere que se le escriba el caso

${ }^{2}$ Añade R.N. una consideración más: la Celestina y otras "obras que dejaron huella" en el Lazarillo (y de las cuales me ocuparé después) contienen Argumentos; "el propio Alfonso de Valdés escribe un Argumento después del Prólogo en el Diálogo de las cosas acaecidas en Roma”; ergo, también el Lazarillo debió tenerlo. (¡Como si no fuera Argumento más que suficiente lo que acerca de su vida dice Lázaro en esos primeros párrafos que se imprimieron como Prólogo!)

${ }^{3}$ La "carrera de vivir" no ha sido fácil para Lázaro. No es mérito - dice al comienzo- el haber heredado "grandes estados" (o sea, una situación económico-social estable); pero sí es mérito que un desheredado perfecto, como él lo es, "con fuerza y maña” (aguantando los más duros golpes y aguzando finamente las entendederas) llegue a ser dueño y señor de su vida. "Válete por ti", le dice su madre en la despedida; y el ciego: "Aprende, que el mozo de ciego un punto ha de saber más que el diablo", tras lo cual reflexiona Lázaro: "Verdad dice éste...: me cumple avivar el ojo y avisar, pues solo estoy, y pensar cómo me sepa valer". A pesar de su dureza (mejor dicho: a causa de su dureza), las lecciones que recibe Lázaro del primer amo son fundamentalísimas: "Después de Dios, éste me dio vida y, siendo ciego, me alumbró y adestró en la carrera de vivir". La vida y el vivir reaparecen a lo largo de la obra: "Viendo el Señor mi rabiosa y continua muerte, pienso que holgaba de matarlos para darme a mí vida [en las comilonas de los mortuorios]"; "comienzo a barrer la casa con mucha alegría, pareciéndome con aquel remedio remediar dende en adelante la triste vida"; "noche y día estaba pensando la manera que ternía en substentar el vivir"; "Allí lloré mi trabajosa vida pasada y mi cercana muerte venidera"; "pasando la vida que digo, quiso mi mala fortuna... que en aquella trabajada y vergonzosa vivien$d a$ ['manera de vivir'] no durase"; "A mí diéronme la vida unas mujercillas hilanderas de algodón"; "Éste fue el primer escalón que yo subí para venir a alcanzar buena vi$d a$ "; "Y pensando en qué modo de vivir haría mi asiento..."; "un oficio real..., en el cual el día de hoy vivo"; "Malas lenguas... no nos dejan vivir", pero, despreciando a los viles chismosos, "tengo paz en mi casa". El leitmotiv falta sólo en el tractado IV (que es brevísimo) y en el V (donde Lázaro no habla de sí, sino de las tretas del buldero). 
muy por extenso, comenzaré desde el principio. Pues bien, a mí llaman Lázaro de Tormes, porque nací literalmente en el río Tormes..., etc., etc. No hay la menor solución de continuidad entre estas líneas iniciales y las finales, donde Lázaro, de manera apenas velada, dice que su victoria en la lucha por la vida es tan digna de recordación como las victorias de Carlos V, aunque las de éste sean de índole política y la suya de índole moral (y aunque la suya no sea celebrada en Toledo con "grandes regocijos"). La división de la carta de Lázaro en ocho secciones (o ahora en diez) no tiene razón de ser: es superimpuesta y artificial 4 .

Hay otra innovación que atañe a la estructura. En su penúltimo parlamento, dirigido al Arcipreste, se refiere Lázaro a las "malas lenguas" que dicen que su mujer, "antes que conmigo casase, había parido tres veces, hablando con reverencia de Vuestra Merced, porque está ella delante”. Lázaro, muy cortésmente, le ‘pide perdón’ al Arcipreste por haber soltado el verbo parir, tan crudo, tan descarado, estando allí presente la incriminada, o sea su mujer. No hay en este parlamento la menor complicación gramatical: poco antes ha dicho Lázaro que la conversación con el Arcipreste transcurrió en presencia de la mujer ("delante de ella"); y el parlamento está dirigido al Arcipreste ("Señor -le dije-, yo determiné...", etc.). Pero R.N. altera el texto: pone punto en "había parido tres veces" e imprime el resto del parlamento en párrafo aparte, como oración independiente. En efecto - dice-, en esa oración (tan rara, por cierto: sin verbo principal) ya no habla Lázaro con el Arcipreste; el "Vuestra Merced" que usa no se refiere a dicho "Señor", sino a la persona que le pidió noticias de su vida. Por lo visto, R.N. piensa que el "Vuestra Merced" del Prólogo quedó marcado para siempre como designación de una sola persona ${ }^{5}$. Y en cuanto al ella de "porque está ella delante", dice que no se refiere ya a la mujer de Lázaro, sino a "Vuestra Merced". De lo

${ }^{4}$ Así lo probó cumplida y brillantemente Francisco Rico, "La princeps del Lazarillo", Homenaje a Eugenio Asensio, Madrid, 1988, pp. 417-446. Y lo curioso es que R.N. lo acepta. En nota de la p. 80 se lee: "Es muy plausible, como ya indica Rico ["como demuestra Rico", sería mejor], que ninguno de los epígrafes... los escribiera el autor, ya que Alfonso de Valdés no vio impresa su obra". (Además de que Rico no mete a Valdés en su razonamiento, el "ya que" consecutivo es un non sequitur, pues bien pudo Valdés escribir los epígrafes aunque no haya visto impresa "su" obra.) Y en nota de la p. 111: "Es opinión ampliamente admitida que no se deben al autor ni la división en [prólogo y] capítulos ni los epígrafes que los encabezan”. No creo que sea "ampliamente" admitida, pues veo que la división persiste. "En rigor - dice muy bien Rico, loc. cit., p. 434, nota 28-, una edición crítica debiera confinar [los epígrafes] al aparato", o sea a notas de pie de página, dejando un texto limpio y corrido, sin esos estorbos. Ciertamente sería mucho mejor. Desde luego, se ahorrarían no pocas especulaciones ociosas.

${ }^{5}$ En su ed. de Cátedra, 1987, p. 9, nota 20, observa F. Rico que Lázaro también trata al escudero de "Vuestra Merced", o sea que le habla de usted. 
cual deduce que quien le pidió a Lázaro noticias de su vida fue una dama (ella). Verdad es que la dama no se halla allí, pero sí "«está delante» al leer la carta"6 (pp. 17-18 y 208, nota). R.N. está completamente segura de su extraordinario hallazgo: "Siempre se ha visto la figura de un clérigo en «Vuestra Merced»” (p. 17) ${ }^{7}$. ¡Pues no! ¡Es una dama!

Y el hallazgo conduce a otros hallazgos mucho más impresionantes, que atañen al porqué del Lazarillo, a su significación misma. Los elementos de esta novela de la novela son estupendos. Júzguese, si no. La dama en cuestión, a pesar de que no vive en Toledo, por alguna razón se confiesa con el Arcipreste de la toledana iglesia de San Salvador, y le han llegado rumores de que su confesor vive amancebado con la mujer de Lázaro. Ahora bien, un sacerdote concubinario deja de ser digno de confianza: será capaz de contarle a su manceba los pecados de la dama, y la manceba podrá contárselos a Lázaro, que es un "marido complaciente", y Lázaro, pregonero de oficio, será capaz de pregonar los pecados de la dama en las calles y plazas de Toledo. A la dama se le ocurre entonces la gran idea: que sea el propio Lázaro quien la saque de dudas ${ }^{8}$.

La estupenda novela ha nacido, por una parte, de la interpretación del penúltimo parlamento de Lázaro ("Vuestra Merced" y "está ella delante"), y por otra, naturalmente, de la convicción de que el "caso" que se propone narrar Lázaro (Prólogo) no es sino el "caso" del final ("hasta el día de hoy nadie nos oyó sobre el caso"), y de que este segundo "caso" significa, fuera de duda, 'amancebamiento'. R.N. no ha necesitado abundar en el asunto: tiene detrás las docenas de lazarillistas que sí han abundado, y para los cuales el amancebamiento ha adquirido ya el status de dogma ${ }^{9}$. Así, pues, cuando decla-

${ }^{6}$ Cf. p. 18, nota: en cierto poder que Alfonso de Valdés da a sus hermanos se lee: “...mis hermanos, que estáis ausentes, bien y como si fuéredes presentes”. Esto, según R.N., "sería equivalente [!] al «porque está ella delante»".

${ }^{7}$ Me llama la atención el siempre. Según F. Lázaro Carreter, "Vuestra Merced" es simplemente un "socarrón impenitente" que le gasta a Lázaro "la más sangrienta broma: hacerle contar, por irrisión, su vida". No sé quiénes ven en "Vuestra Merced" la "figura de un clérigo" (ni, por supuesto, en qué se basan).

8 No invento nada: “¿Por qué le interesa el «caso» a la dama a quien Lázaro escribe? Porque el Arcipreste es su confesor, a quien [ella] confía los secretos de su alma" (p. 19); "No es raro que la dama esté inquieta por los rumores que le han llegado sobre la conducta de su confesor y que le pregunte a Lázaro... si son ciertos" (p. 22); "Nadie mejor que Lázaro para contarle a Vuestra Merced el «caso», porque él es el marido complaciente que tapa el amancebamiento" (p. 51); "El Arcipreste, confesor de los pecados ajenos, ¿sabrá guardarlos en secreto? ¿O se los contará a su manceba, a quien tal vez se le ocurra comentárselos a su marido, Lázaro de Tormes, pregonero de Toledo?" (p. 87); "El secreto de confesión [resulta] amenazado con la profesión del marido de la amante, pregonero" (p. 19).

9 A mí (cf. "Contra los denigradores de Lázaro de Tormes", NRFH, 50, 2002, sobre todo pp. 436-437) siempre me ha asombrado -y me sigue (y sin duda me 
ra que el caso es el "auténtico centro de la obra" (p. 19), no está diciendo nada nuevo. En cambio, cuando declara con idéntica seguridad que "lo que quiere contar Lázaro no es su vida, sino el «caso" con que cierra su relato" (p. 15), que "contar el «caso» es la razón de la escritura de Lázaro, y no contar su vida” (p. 20), sí está diciendo algo muy novedoso. Creo que ningún crítico había llegado a tal extremo: ¡la Vida de Lazarillo de Tormes se nos presenta como obra de un vecino de Toledo que no quiere contar su vida! De manera que la dama ha invitado a Lázaro a relatar, lo más detalladamente posible ("y pues vuestra Merced escribe se le escriba y relate el caso muy por extenso"), qué es lo que andan diciendo sobre su mujer las malas lenguas, y Lázaro, encantado con la invitación, le contesta que nació en una aceña, que fue mozo de ciego, etc., ¡todo "muy por extenso"! La sorprendente declaración de que lo que quiere Lázaro es contar el "caso" (y no su vida) parece destinada a apuntalar la idea de que, hasta el día de hoy, las lecturas del Lazarillo han sido imperfectas: gracias al descubrimiento de la dama, "el "caso» cobra nueva intensidad", y quedamos así preparados para ver "hasta dónde llega la agudísima sátira erasmista que hay en el Lazarillo" (p. 19) ${ }^{10}$.

"Lázaro no es un pícaro", dice también R.N. (p. 37). En esto estoy completamente de acuerdo, pero no por la razón que ella da: "no es un pícaro porque nunca aparece la palabra en la obra" (el autor pudo haber hecho redomadamente pícaro a Lázaro sin necesidad de usar la palabra), sino por otras razones (cf. mi art. cit., sobre todo pp. 449-450). ¿Qué es entonces Lázaro? Es un personaje muy "bien trazado", y aun "entrañable", al punto de que "ha desviado la atención del lector hacia él, cuando su misión era que [el lector] se fijara sobre todo en lo que él veía y decía" (p. 38). Para que la atención deje de "desviarse", basta no perder de vista que Lázaro es sólo una especie de cámara de televisión que Alfonso de Valdés utiliza para elaborar su serie de "documentales”. Valdés, dice R.N., inventó a Lázaro como "guía ideal para ver y contar" (p. 38); "no son amos elegidos al azar los de Lázaro; no es la vida del muchacho el objetivo de la

seguirá) asombrando- la casi unanimidad con que los críticos identifican los dos $c a$ sos, siendo el sustantivo caso tan insustancial, tan incoloro, tan bueno para cualquier cosa, y, sobre todo, estando tan claro que el del prólogo se refiere a la satisfacción "existencial" de Lázaro (el vivir "con tantas fortunas, peligros y adversidades").

${ }^{10}$ No puedo menos de preguntarme quién es el blanco de la "agudísima sátira": ¿Lázaro, su mujer, el Arcipreste, o el conjunto de los tres? Pero en España, como en el resto de Europa, abundaban los cuentos, las coplas, los chistes, los refranes sobre clérigos y frailes salaces, sobre maridos complacientes, sobre mujeres desvergonzadas. No hacía falta acudir a Erasmo, -que, por lo demás, nunca se ocupó de eso. (El final de la novela no es difícil de imaginar: si el "auténtico centro de la obra", o sea el amancebamiento, es un hecho, habrá que pensar que la dama, al acabar de leer la carta de Lázaro, decide nunca más confesarse con el Arcipreste.) 
sátira; él sufre, mira, cuenta" (p. 51); a Valdés "le basta dejar a su personaje que vea, que note, que cuente, porque es sólo su voz la que se oye" (p. 82); Valdés "habla por boca de Lázaro, le hace vivir, ver y notar lo que él denuncia desde su pensamiento erasmista” (p. 89).

En las citas del párrafo anterior se repiten ver, mirar, deciry contar, pero no hay sino un caso de sufrir y uno de vivir. Como si esto fuera secundario o accesorio. Para mí, en cambio, el "vivir" y el "sufrir" de Lázaro son lo esencial. Si "es sólo su voz la que se oye”, es porque así tenía que ser: así cobran vida sus experiencias y sus reflexiones. Lázaro, que se moldea a sí mismo en cuanto persona mediante su experiencia de la vida, se hace a la vez a sí mismo en cuanto personaje literario mediante su palabra. El que sea un personaje "entrañable" y "bien trazado" estorba, según R.N., para ver que el autor lo inventó exclusivamente para very contar. Según yo, lo "bien trazado" y lo "entrañable" es lo que importa11. Por supuesto que el autor está emitiendo mensajes erasmianos (reformistas). Es casi como si lo oyéramos: "Señores, ¡esto anda mal! ¡Esto no puede ser! Esa avaricia del clero, esa escandalosa conducta de tantos frailes, esa vana superstición de la "honra" (trabada con la de la limpieza de sangre), ese negocio descaradamente simoníaco de las bulas de indulgencia, ese olvido de la philosophia Christi...". Sí, pero no lo hace en el tono didáctico del Enchiridion militis christiani, sino con los acentos, aún más persuasivos, de quien ha experimentado directamente esas cosas que andan mal y que preocupan a Erasmo y a los erasmistas.

Los mensajes de Erasmo son civilizadores, tal como lo son, a su manera, los de Castiglione en su Cortigiano; batallas contra la barbarie y los valores espurios (las exterioridades en que se ahoga el interior); batallas contra "errores comunes" y los viri obscuri. Las indulgencias que se venden son una burla; las exigencias de la "honra", en virtud de las cuales el escudero no alcanza a vivir siquiera "a pan y agua", sino sólo "a agua y humos", son una solemne tontería; y el famoso "honor conyugal", que no queda afectado cuando el marido comete infidelidades, pero sí, ¡y cómo!, cuando las comete la mujer (peor: incluso cuando sólo hay "rumores" de que las comete), de tal manera que el marido tiene el deber de lavar con sangre la deshonra, no es sino brutalidad. El mensaje de Erasmo es simple y amplísimo: “'Seamos justos! ¡Seamos sensatos! El matrimonio es una institución social valiosa; vale la pena mantenerla; hay que salvar la

${ }^{11}$ De hecho, en la interpretación de R.N., Lázaro no tiene estatura de personaje, salvo en los párrafos finales, los del "amancebamiento"; ahí deja de ser figura plana y adquiere momentáneo relieve con su papel de presunto "marido complaciente". Tampoco su mujer alcanza a ser personaje: "no existe más que como amante del Arcipreste" (p. 38), o sea en cuanto elemento del "caso". Como si no contara su enérgico repudio de los "rumores"; como si no viniera a cuento el respeto y el amor con que Lázaro la trata. 
concordia conyugal a fuerza de mutua buena voluntad"12. Pero las malas lenguas tienen el poder de arruinar la concordia. Los "rumores" son, por naturaleza, cosa ambigua: pueden ser verídicos y pueden ser mentirosos (y en rumores ambiguos se fundan los muchos críticos que, como R.N., dan el amancebamiento como un hecho). En vez de actuar atolondradamente, Lázaro usa la razón que Dios le dio y que él supo afinar, examina el "caso" junto con su mujer y el Arcipreste y saca sus propias conclusiones. El vivir tiene como correlato el dejar vivir. Cada ser humano es responsable de su vida, cada cual es dueño de su conciencia; su mujer tiene la condición plena de ser humano (y es "tan buena mujer" como cualquiera de las que viven "dentro de las puertas de Toledo".)

El mensaje de cordura es aquí tan revolucionario que, según yo, los críticos se han tapado las orejas para no oírlo. Lázaro se desentiende erasmianamente de la superstición de la "honra" exterior y se queda con su honra íntima intacta. Termina su autobiografía con la frente muy en alto. (Y esta terminación, medida con la vara de El médico de su honra, es lo menos calderoniano que se pueda imaginar.) En resumen, mi interpretación del Lazarillo se opone polarmente a la de R.N.; para mí, el Lazarillo es un auténtico (y perfecto) Bildungsroman.

La parte más llamativa de la "tesis" de R.N., o sea la atribución del Lazarillo a Alfonso de Valdés, no necesita comentarios prolijos. Esta atribución fue propuesta en 1976 por Joseph V. Ricapito ${ }^{13}$, pero él se

12 Sobre las obras en que Erasmo habla del matrimonio, especialmente el coloquio Mempsigamos, véase Marcel Bataillon, Erasmo y España, 1966, pp. 287-291. Bataillon ofrece datos interesantes en cuanto a la influencia del Mempsigamos en Alfonso de Valdés (p. 397: Diálogo de Mercurio y Carón), en Juan Luis Vives (p. 635), en Pedro de Luxán (p. 649) y en Cervantes (p. 782: Persiles). Todos estos autores hacen recaer la carga en la mujer mucho más que en el marido; todos piensan que es ella la que debe velar por la concordia, esto es, la que debe ceder. De ahí el especial interés de este otro dato (p. 288): algunas lectoras de la traducción del Mempsigamos por Diego Morejón, publicada en 1527, encontraron injusto ese desequilibrio; así lo refiere el erasmista anónimo que en 1528 imprimió una edición retocada de dicha traducción, y lo que les responde a las inconformes es esto: "Cuando dos amigos riñen, el que los quiere poner en paz suele acudir al más prudente, dándole a entender cómo a él toca suplir con su prudencia las faltas del otro" (las mujeres son, por naturaleza, más prudentes que los hombres). - Entre los que escucharon el mensaje del Mempsigamos no menciona Bataillon al autor del Lazarillo (que, según él, no era erasmista). Pero no está de más observar que en el Lazarillo es el marido quien se hace cargo de esa prudencia salvadora de la concordia conyugal. (Añadiré que no deja de causarme cierta desazón el que Bataillon no haya visto lo que para mí es tan claro.)

${ }^{13}$ Manuel J. Asensio, en 1959, se había inclinado por Juan de Valdés. Dijo que si no es él el autor, "ha de parecérsele mucho" (y cabe notar que Juan y Alfonso se parecían mucho así en lo intelectual como en lo físico, pues eran hermanos gemelos": cf. Bataillon, op. cit., p. 430, fin de la nota 16). Ya en 1888, Alfred Morel-Fatio -maestro de Bataillon- había dicho que un libro como el Lazarillo tenía que ser obra de un erasmista, y había sugerido los nombres de Juan y de Alfonso. 
limitó a lanzar una "hipótesis basada en intuiciones más que en pruebas" (p. 93), mientras que R.N. se ha propuesto no basarse sino en pruebas. El erasmismo de Alfonso de Valdés está, desde luego, fuera de toda duda. Aquí no hace falta prueba alguna. Bien pudo ser él el autor del inmortal librito. (Y si lo fuera, mi interpretación, mi manera de leerlo, no variaría ni un ápice.) Lo malo es que no hay un documento fehaciente que demuestre que así es. Las pruebas que ofrece R.N. son éstas:

"Ninguna fecha dentro de la obra o en relación con ella es posterior al período que va desde finales de 1529 a septiembre de 1532, en que Alfonso de Valdés escribiría el Lazarillo" (p. 27) ${ }^{14}$ : la batalla de los Gelves ocurrió en 1510, y la entrada de Carlos V en Toledo, donde presidió unas Cortes, ocurrió en 1525. "No tiene ningún sentido que en 1552 o 1553 [fecha muy probable de la $1^{\text {a }}$ ed. del Lazarillo] un supuesto genial escritor desconocido escriba una obra con una cronología interna asentada en hechos históricos sucedidos más de veinticinco años antes" (p. 25). Es ésta la única alusión a candidaturas rivales, como la de Hurtado de Mendoza y la de fray Juan de Ortega (cuyos nombres nunca menciona R.N.), y el aludido debe de ser Ortega, pues sólo a él le queda lo de "desconocido". Yo, en cambio, estoy convencido de que el autor del Lazarillo es este "desconocido". El inequívoco testimonio de fray José de Sigüenza es el documento fehaciente de que carece la candidatura de Valdés; nadie ha sido capaz de refutar ese testimonio ${ }^{15}$, y el silencio de R.N. me parece una falla

${ }^{14}$ Los dos Diálogos de Valdés, dice R.N., p. 35, "se debieron de publicar en Italia después de su muerte, y probablemente también su Lazarillo de Tormes". De hecho, ninguna de las ediciones italianas conocidas de los Diálogos está fechada, pero es lógico suponer que la del de las cosas acaecidas en Roma se hizo "en caliente", quizá en el propio año 1527.

15 Ortega, como reconoce F. Rico (ed. del Lazarillo, p. 34*), es "el más antiguo y sin duda el más plausible de los candidatos a la paternidad del Lazarillo". Yo no digo "el más plausible", sino el único seguro. Cf. mi art. cit., p. 447, y sobre todo mi reseña del Lazarillo de A. Martino, NRFH, 50 (2002), pp. 254-255. Vale la pena leer con atención el testimonio de SigüEnZa (Historia de la orden de San Jerónimo, tomo 12 de la $N B A E$, p. 145) acerca de Ortega: "Dicen que siendo estudiante en Salamanca, mancebo, como tenía un ingenio tan galán y fresco, hizo aquel librillo que anda por ahí, llamado Lazarillo de Tormes, mostrando en un sujeto tan humilde la propiedad de la lengua castellana, y el decoro de las personas que introduce, con tan singular artificio y donaire, que merece ser leído de los que tienen buen gusto. El indicio desto fue haberle hallado el borrador en la celda, de su propia mano escrito". El dicen se refiere sólo a la fecha de composición (de eso no está seguro Sigüenza: bien pudo Ortega escribir el libro siendo ya fraile); pero el "haberle hallado el borrador en la celda" es un hecho; por eso he subrayado la palabra indicio, que obviamente no tiene el significado desvaído de 'barrunto' o 'sospecha', sino el fuerte y preciso que tiene indicium en latín: 'revelación', 'prueba'. También hay que aquilatar la frase "merece ser leído de los que tienen buen gusto": los lectores que entienden (los capaces de "ahondar", como dice Lázaro) verán que no se trata de una simple ristra de cuentecillos, con una vulgar historia de cuernos al final. 
crítica. Nada de lo que ella argumenta sirve para eliminar a Ortega. Los "hechos históricos" de esos primeros decenios del siglo XVI impresionaron no sólo a Alfonso de Valdés, sino a todos sus coetáneos, uno de ellos fray Juan de Ortega ${ }^{16}$.

La misma réplica sirve para los demás argumentos de R.N. Los dos espaderos mencionados en el Lazarillo, Antonio y Cuéllar, eran conocidos de todo el mundo (las espadas que fabricaban eran proverbialmente las buenas). Y de las lecturas cabe decir otro tanto. Según R.N. (pp. 61-83), en el Lazarillo hay huellas de los libros que se leían hacia 1530: la Celestina, la Propaladia, la Tebaida, la Lozana andaluza, las obras de fray Antonio de Guevara ${ }^{17}$. Sí: salvo quizá la Lozana andaluza, son cosas que todos leían (junto a la Cárcel de Amor, los Amadises, el Cancionero general, etc.). Sería muy raro que Alfonso de Valdés y fray Juan de Ortega las desconocieran ${ }^{18}$.

Es fácil de explicar la anonimia del Lazarillo: tal fue la intención del autor. Así como fray Luis de León, catedrático de Biblia, le permitió al Brocense publicar algunas de sus traducciones de Horacio, pero sin su nombre, así fray Juan de Ortega, elegido superior general de su orden justamente en 1552, quiso que su libro juvenil se imprimiera anónimo. Si yo hiciera una nueva edición del Lazarillo (la enésima), no estamparía el nombre de Ortega en la portada. Sería una falta de respeto. La anonimia del Lazarillo es parte muy importante de su historia, y aun de su sentido.

Antonio Alatorre

El Colegio de México

${ }^{16}$ Hacia 1539 era Ortega hombre maduro, puesto que Carlos V quiso que fuera el primer obispo de Chiapas (cargo que más tarde desempeñaría fray Bartolomé de las Casas); debe de haber nacido a fines del siglo xv, igual que los hermanos Valdés.

17 Añado, marginalmente, que esas "huellas" son invisibles para mí. He aquí un ejemplo. En la Celestina, Lucrecia felicita a la vieja al verla acompañada de "mucha gente" (las dos pupilas y los dos criados de Calisto), y Celestina le contesta: "¿Por mucha has ésta? Bien parece que no me conociste en mi prosperidad, hoy ha veinte años...”, etc.; en seguida evoca una a una sus glorias pasadas, y añade: "Mi honra llegó a la cumbre, según quien yo era". Esto, según R.N. (pp. 62-63), dejó su "huella" en el párrafo final del $L a$ zarillo: "Pues en este tiempo estaba en mi prosperidad y en la cumbre de toda buena fortuna". Yo no la veo; y estoy seguro de que cualquier lector normal del Lazarillo pensará que el autor pudo perfectamente atinar con las palabras prosperidady cumbre sin necesidad de la Celestina (lo cual, por supuesto, no es negar que la haya leído).

18 Transcribo otros argumentos que subsidiariamente aduce R.N. en favor de Alfonso de Valdés: 1) el autor del Lazarillo "muestra una clara predilección por el empleo del verbo acaecer frente a sinónimos como sucedery acontecer; la misma preferencia se advierte en los diálogos de Alfonso de Valdés" (p. 126, nota) [cf. Diálogo de las cosas acaecidas en Roma]; 2) en el Lazarillo "abandona [Valdés] el género del diálogo y escoge el de la carta, que también domina, porque es el secretario de cartas latinas del Emperador" (p. 39); 3) Valdés "utiliza el término caso para referirse a un asunto esencial, el saco de Roma”, y el mismo término caso se utiliza dos veces en el Lazarillo. (Me abstengo de comentarios.) 
